\title{
Potential antifungal effects of silver nanoparticles (AgNPs) of different sizes against phytopathogenic Fusarium oxysporum f. sp. radicis-lycopersici (FORL) strains
}

\author{
Ilgin Akpinar ${ }^{1}$ (D) $\cdot$ Muammer Unal $^{2}$ (D) Taner Sar $^{3}$ (D)
}

Received: 9 January 2021 / Accepted: 18 March 2021 / Published online: 26 March 2021

(c) The Author(s) 2021 OPEN

\begin{abstract}
Fusarium species are the primary fungal pathogen affecting agricultural foodstuffs both in crop yield and economic loss. Due to these problems, control of phytopathogenic fungi has become one of the critical problems around the World. Nanotechnology is a new technology with potential in many fields, including agriculture. This study focused on determining potential effects of silver nanoparticles (AgNPs) with different nanosizes (3, 5, 8 and $10 \mathrm{~nm}$ ) and at different concentrations (12.5-100 ppm) against phytopathogenic Fusarium oxysporum f. sp. radicis-lycopersici (FORL) strains. The maximum antifungal activity was achieved by decreasing nanosize and increasing concentration of AgNPs. Mycelium growth abilities were decreased about $50 \%, 75 \%$ and $90 \%$ by AgNPs treatment with $3 \mathrm{~nm}$ sizes at $25 \mathrm{ppm}, 37.5 \mathrm{ppm}$ and $50 \mathrm{ppm}$ concentrations, respectively. The productivity of fungal biomass in the liquid growth media was found to be too limited at the 25-37.5 ppm of AgNPs concentrations with all sizes. In addition, both septation number and dimensions of micro- and macroconidia were found to be gradually decreased with the application of silver nanoparticles. This work showed that the low concentration of AgNPs could be used as potential antifungal agents and applied for control of phytopathogens.
\end{abstract}

Keywords Metal-based nanoparticles · Plant pathogens · Antimicrobial · Fungal inhibition

\section{Introduction}

Around the world, the yield and quality of agricultural products continue to be gradually decreased every year due to plant diseases. Plant diseases are a worldwide problem related to food security. Fusarium is one of the most significant and widespread wilt pathogens causing diseases in agricultural products [1]. Fusarium species can also produce mycotoxin in several kinds of cereals, fruits, and vegetables [2]. F. oxysporum known as potential plant pathogenic fungi have been able to grow and survive in soil and on various organic materials for a long time [3]. F. oxysporum is a soilborne pathogen that attacks the roots of the plant and considered as a limiting factor for tomato production $[4,5]$.

The different types of chemicals, pesticides and fungicides have been applied to eliminate fungal contamination. These treatments can also be responsible for environmental pollution and health hazards [6, 7]. Additionally, the use of agrochemicals may support the development of resistant pathogens while reducing the adverse effects of plant diseases [8]. They cause undesirable effects on non-target organisms due to overuse of pesticides. The most important of these effects is that the pesticides are included in the food chain and leave chemical residues on non-target organisms. For these reasons, alternative and

Taner Sar, st.taner@gmail.com; taner_sar@hb.se | ${ }^{1}$ Institute of Graduate Studies in Science, Istanbul University, Istanbul, Turkey. ${ }^{2}$ Department of Biology, Faculty of Science, Section of Botany, Istanbul University, Istanbul, Turkey. ${ }^{3}$ Swedish Centre for Resource Recovery, University of Borås, 50190 Borås, Sweden. 
potential antifungal agents instead of these chemicals should be investigated.

Recently, several metallic nanoparticles (silver, zinc, copper, titanium etc.) have been investigated as antimicrobial agents for the control of microorganisms including phytopathogens $[9,10]$. Among them, silver is well known for its antimicrobial activity since ancient times [11-13]. Also, silver nanoparticles (AgNPs) prevent resistance development of pathogens by increasing antimicrobial activity [14]. Due to these properties, it can be used safety as an alternative to synthetic fungicides in the control of plant pathogens. It has been reported that the antimicrobial effect of nanoparticles (metal/metal oxide, metalloid and non-metal nanomaterials) on test pathogens are based on size and dose dependent $[15,16]$. The size of nanoparticles can effect microstructure and mechanical properties [17]. Nanoparticles are tend to attack a wide variety of biological processes, including cell membrane structure and function in microorganisms [18]. Similarly, AgNPs also inhibit the expression of proteins associated with ATP production [19]. These properties of AgNPs have attracted many practitioners worldwide to use it in various applications such as water purification [20], food packaging [21], antibacterial, antifungal, anti-inflammatory, anticancer, and therapeutic agents [14, 22-24].

In this study, potential antifungal effects of the silver nanoparticles against Fusarium oxysporum f. sp. radicislycopersici strains isolated from the eastern Mediterranean region of Turkey was aimed to determine. Then, the effect of both various sizes (3-10 nm) and different concentrations (12.5-100 ppm) of silver nanoparticles in determining their antifungal activity was investigated. In addition, the morphological characterization (dimension and septation) of microconidia and macroconidia of FORL strains exposed with silver nanoparticle was determined.

\section{Material and methods}

\subsection{Fungal strains}

In this work, six different Fusarium oxysporum f. sp. radicislycopersici Jarvis Shoemaker isolates (AY5, H2, JR, SC, TA4, and TR1) obtained from Eastern Mediterranean Agricultural Research Institute (Adana, Turkey) were used in the experiments. Among them, 5 FORL strains (AY5, H2, SC, TA4, and TR1) were originated from the eastern Mediterranean region of Turkey and the other one (JR) was originated from Japan [1]. These strains were maintained on Potato Dextrose Agar (PDA; Merck, Darmstadt, Germany) plates containing $4 \mathrm{~g} / \mathrm{L}$ potato extract, $20 \mathrm{~g} / \mathrm{L}$ glucose, and $15 \mathrm{~g} / \mathrm{L}$ agar.

\section{SN Applied Sciences

\subsection{Silver nanoparticles}

Four different sizes of AgNPs nanoparticles ( $3 \mathrm{~nm}, 5 \mathrm{~nm}$, $8 \mathrm{~nm}$, and $10 \mathrm{~nm}$ ) used in this experiment were provided by Nanografi Inc. (Jena, Germany). A stock solution of AgNPs at a concentration of $1000 \mathrm{ppm}$ was prepared and then added to growth media at different initial AgNPs concentrations (12.5-100 ppm). All AgNPs solutions were freshly prepared and used.

\subsection{Culture conditions}

The fungal strains were precultured on PDA (Merck, Darmstadt, Germany) medium in a $90 \mathrm{~mm}$ diameter petri dish at $25^{\circ} \mathrm{C}$ for 3 days in an incubator (Binder, Germany) under dark conditions. Additionally, the fungal strains were incubated in Potato Dextrose Broth (PDB containing $4 \mathrm{~g} / \mathrm{L}$ potato extract and $20 \mathrm{~g} / \mathrm{L}$ glucose; Merck, Darmstadt, Germany) medium at $25^{\circ} \mathrm{C}$ and $150 \mathrm{rpm}$ for 7 days under dark conditions (Edmund Buhler, Germany). To determine the antifungal activities of AgNPs, fungal strains were performed using PDA and PDB for mycelial and fungal growth inhibitions, respectively.

\subsection{Mycelial growth inhibition (MGI)}

The mycelial growth inhibition (MGI) of Fusarium strains was evaluated using by agar diffusion method on PDA [25]. PDA was sterilized by heating at $121^{\circ} \mathrm{C}$ for $15 \mathrm{~min}$. Then the stock nanoparticle solution was transferred into the PDA to be obtained different initial AgNPs concentrations (to make up 12.5, 25, 37.5, and $50 \mathrm{ppm}$ ).

The agar plates were prepared by flooding pre-grown agar plates with $20 \mathrm{~mL}$ distilled water, and fungal spores were brought into suspension using by a sterile L-shape plastic spreader. PDA plates were inoculated with $100 \mu \mathrm{L}$ spore suspension and spread with new sterile L-shape plastic spreader. The new plates were incubated at $25^{\circ} \mathrm{C}$ for 3 days in an incubator (Binder, Germany) under dark conditions.

The pre-grown agar plates were punched using by a sterile cork borer ( $8 \mathrm{~mm}$ size) and transferred to the centre of each fresh PDA agar treated with AgNPs nanoparticles. Then, the cultures were incubated at $25^{\circ} \mathrm{C}$ for 7 days, under the dark conditions. After the incubation, the colony diameters were measured in millimetres. FORL strains were also grown in PDA without nanoparticles and evaluated as a positive control.

The percentage of mycelial growth inhibition (MGI) was calculated according to the following formula [25]; 
$M G I(\%)=\left[\frac{d c-d t}{d c}\right] \times 100$

where $\mathrm{dc}(\mathrm{mm})$ is the mean fungal growth diameter for the controls and $\mathrm{d} t(\mathrm{~mm})$ is the mean fungal growth diameter for each group treated with AgNPs.

\subsection{Fungal growth inhibition (FGI)}

The fungal growth inhibition ( $\mathrm{FGI}$ ) was determined by the broth-dilution method using PDB [26]. The assay was performed using 96 well polystyrene plates. Each well was filled with PDB treated with AgNPs with different sizes ( $3 \mathrm{~nm}$, $5 \mathrm{~nm}, 8 \mathrm{~nm}$, and $10 \mathrm{~nm}$ ) and at different concentrations (from 12.5 to $100 \mathrm{ppm}$ ).

Fusarium strains were pre-grown on PDA at $25{ }^{\circ} \mathrm{C}$ for 3 days under the dark conditions. The pre-grown agar plates were treated with $20 \mathrm{~mL}$ sterile distilled water, and spore suspensions were obtained using by sterile L-shape plastic spreader. The spore suspensions (final concentration was set as $2.5 \times 10^{4}$ spores $/ \mathrm{mL}$ ) were inoculated into the PDB medium supplemented with AgNPs. PDB treated with only AgNPs (without fungal growth) were used as a blank, PDB incubated with only FORL strains (without nanoparticles) were also used as a positive control. The plates were incubated at $25^{\circ} \mathrm{C}$ for 7 days in the incubator (Binder, Germany) under dark conditions. After the incubation, the fungal growth was measured at $600 \mathrm{~nm}$ using an ELISA plate reader.

The fungal growth inhibition ( $\mathrm{FGl}$ ) was calculated by the following formula with some modifications [26];

$\left.\operatorname{FGI}(\%)=\left[\left(\frac{(\mathrm{Cg}-\mathrm{Cb})-(\mathrm{Tg}-\mathrm{Cb})}{(\mathrm{Cg}-\mathrm{Cb})}\right)\right] \times 100\right]$

where $\mathrm{Cg}$ is the average growth in the control PDB (fungal growth density), $\mathrm{Tg}$ is the average growth in the treated group with AgNPs, and $\mathrm{Cb}$ is the blank.

\subsection{Morphological characterization}

The morphological characterization of six FORL strains was investigated by growing in both PDB and PDB supplemented with AgNPs (at 37.5 ppm and 50 ppm concentrations). The fungal strains were cultivated at $25^{\circ} \mathrm{C}$ for 7 days under dark conditions. After the incubation, the dimensions of microconidia and macroconidia were measured using by an ocular micrometer, and the number of septation of conidia was recorded [27].

\subsection{Statistical analysis}

All experiments were carried out at least three times, and the obtained results were statistically analyzed using
Minitab $17^{\circledR}$. Analysis of variance (ANOVA) using general linear models was carried out, and significant differences were considered at $p$-value $<0.05$ within a $95 \%$ confidence interval. Pairwise comparisons among groups of data were also carried out according to the Tukey's test. All error bars and intervals represent standard deviation.

\section{Results and discussion}

\subsection{Antifungal activities}

Previous studies showed that metallic nanoparticles such as silver, titanium, tin, zinc, and copper having high antimicrobial activity, low toxicity to humans, chemical stability, and inhibition activity against various phytopathogenic microorganisms [28-30]. Therefore, in this work, the AgNPs nanoparticles at different concentrations with various nanometer sizes were tested against the six F. oxysporum FORL strains.

\subsubsection{The mycelial growth inhibition (MGI)}

The mycelial growth inhibition (MGI) of AgNPs at different concentrations with different sizes were analyzed on PDA. The MGI results were given in Fig. 1. The data of the study showed that higher AgNPs concentrations (50 ppm) at all sizes had the highest antifungal activity against all tested strains (Figs. 1, 2). Antifungal activities of higher than $50 \mathrm{ppm}$ concentrations ( $75 \mathrm{ppm}$ and $100 \mathrm{ppm}$ ) were also tested, the results were determined to be similar, and there were no statistically different ( $p$-value $>0.05$; data not shown). Similarly, higher concentrations of silver nanoparticles (100 ppm) have been reported to have most significant inhibition against various plant pathogens [30,31]. When the low sizes of nanoparticles even at low concentrations were applied, the inhibition ratios were increased. When the $3 \mathrm{~nm}$ size of AgNPs was applied, fungal growth of FORL strains was decreased by $20-62 \%$ and $50-76 \%$ at $12.5 \mathrm{ppm}$ and $25 \mathrm{ppm}$ concentrations, respectively (Table 1 ). In addition, in the $3 \mathrm{~nm}$ size of AgNPs treatments, MGI ratios were determined to be at least $75 \%$ by 37.5 ppm treatment and $99 \%$ with 50 ppm treatment. According to MGI ratios, it can be said that the size combined with concentration of nanoparticles have been an important parameter. When the nanometer size was increased to $5 \mathrm{~nm}$, the MGI ratios were generally increased in low concentrations (i.g. 12.5 and 25 ppm); however, MGI ratios were tended to decrease in higher concentrations (i.g. 37.5 ppm and 50 ppm of AgNPs) (Fig. 1). In summary, the mycelium growth was reduced by $50 \%$ and $75 \%$ with AgNPs performed at $25 \mathrm{ppm}$ concentrations with $3 \mathrm{~nm}$ or $5 \mathrm{~nm}$ sizes and $37.5 \mathrm{ppm}$ concentrations with $3 \mathrm{~nm}$ size, 

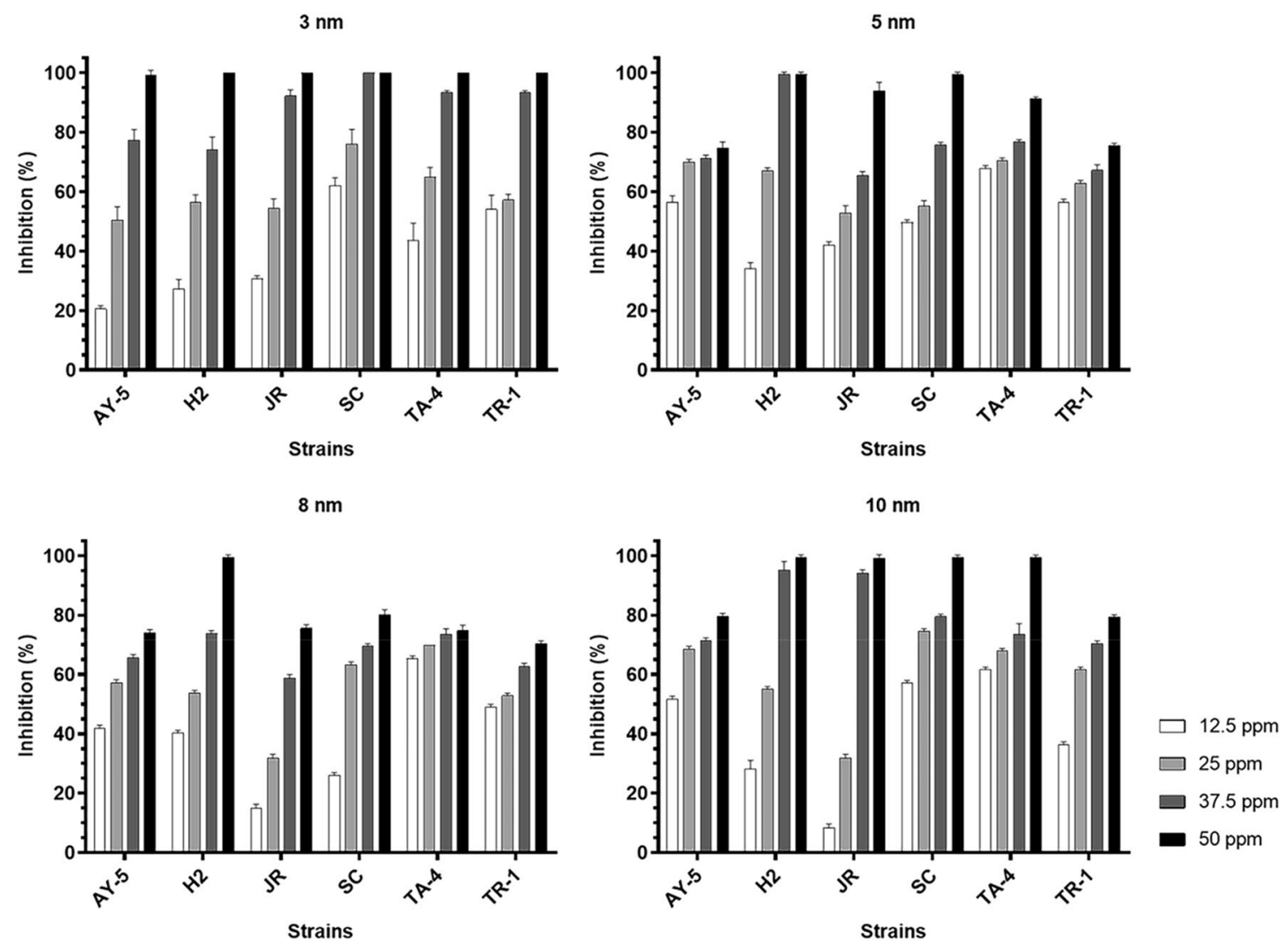

Fig. 1 Mycelial growth inhibition (MGl, \%) of Fusarium oxysporum $\mathrm{f}$. sp. radicis-lycopersici (FORL) strains after application of AgNPs at different concentrations ( $12.5 \mathrm{ppm}, 25 \mathrm{ppm}, 37.5 \mathrm{ppm}$, and $50 \mathrm{ppm}$ ) with different nanoparticle sizes $(3 \mathrm{~nm}, 5 \mathrm{~nm}, 8 \mathrm{~nm}$, and $10 \mathrm{~nm})$.

*Values are averages of 3 individual experiments. Error bars indicate sample standard deviations, which were estimated individually for each average

respectively. Similarly, it has been reported that nanoparticles with smaller sizes have more effective antimicrobial activity against human pathogens (Aeromonas spp., Klebsiella pneumonia, E.coli, Salmonella typhi, Staphylococcus aureus and Yersinia enterocolitica), but their antimicrobial effects decreased as the nanosize were increased [32, 33]. Smaller nanoparticles, like $5 \mathrm{~nm}$, had shown more antimicrobial activity by both increasing membrane permeability and causing cell membrane damage [34].

\subsubsection{The fungal growth inhibition (FGI)}

Previous studies showed that antifungal activities were determined in broth dilution bioassay [35, 36]. Therefore, in this work, silver nanoparticles at different concentrations (12.5-100 ppm) with different sizes $(3-10 \mathrm{~nm})$ were tested in PDB (Table 1). It has been shown that increasing concentrations and decreasing nanometer size of AgNPs resulted in higher antifungal activities for F. oxysporum isolates. The FGl ratios were determined as low at $12.5 \mathrm{ppm}$ concentration of AgNPs with all sizes. The fungal growth of five of the six strains were inhibited at least $90 \%$ at a

concentration of $25 \mathrm{ppm}$. However, the fungal growth of AY-5 strain was reduced ranged from 24 to $32 \%$ at $12.5 \mathrm{ppm}$ and $25 \mathrm{ppm}$ concentrations, and about $70 \%$ at higher than 25 ppm concentrations. For inhibition of Fusarium strains, silver nanoparticles at the $25-50$ ppm concentrations could be used (Table 1).

The antimicrobial activities of silver nanoparticles may be the result of a loss of replication activity that inactivates the cellular proteins and enzymes of the pathogens $[19,37]$. The antimicrobial capacity can also be increased by modifying the surface with the mediations of various extractions or different combinations with antimicrobials [38-40]. Fernández et al. [38] demonstrated that AgNPs biosynthesized from Rhodotorula glutinis had shown more effective antifungal activity. Gajbhiye et al. [39] tested synergistic effects of silver nanoparticles combination with fluconazole against pathogenic fungi. It was concluded that these combinations did not improve the antifungal activity against Fusarium semitectum; however, antifungal activity was enhanced against Trichoderma sp. and Candida albicans. Except for silver-based nanoparticles, other metallic nanoparticles, especially copper, having potential 
Fig. 2 Inhibition effect of silver nanoparticles (AgNPs) with

$3 \mathrm{~nm}$ size against Fusarium oxysporum f. sp. radicis-lycopersici (FORL) strains on PDA

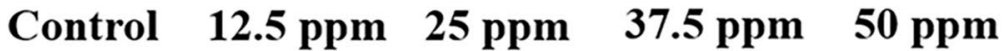

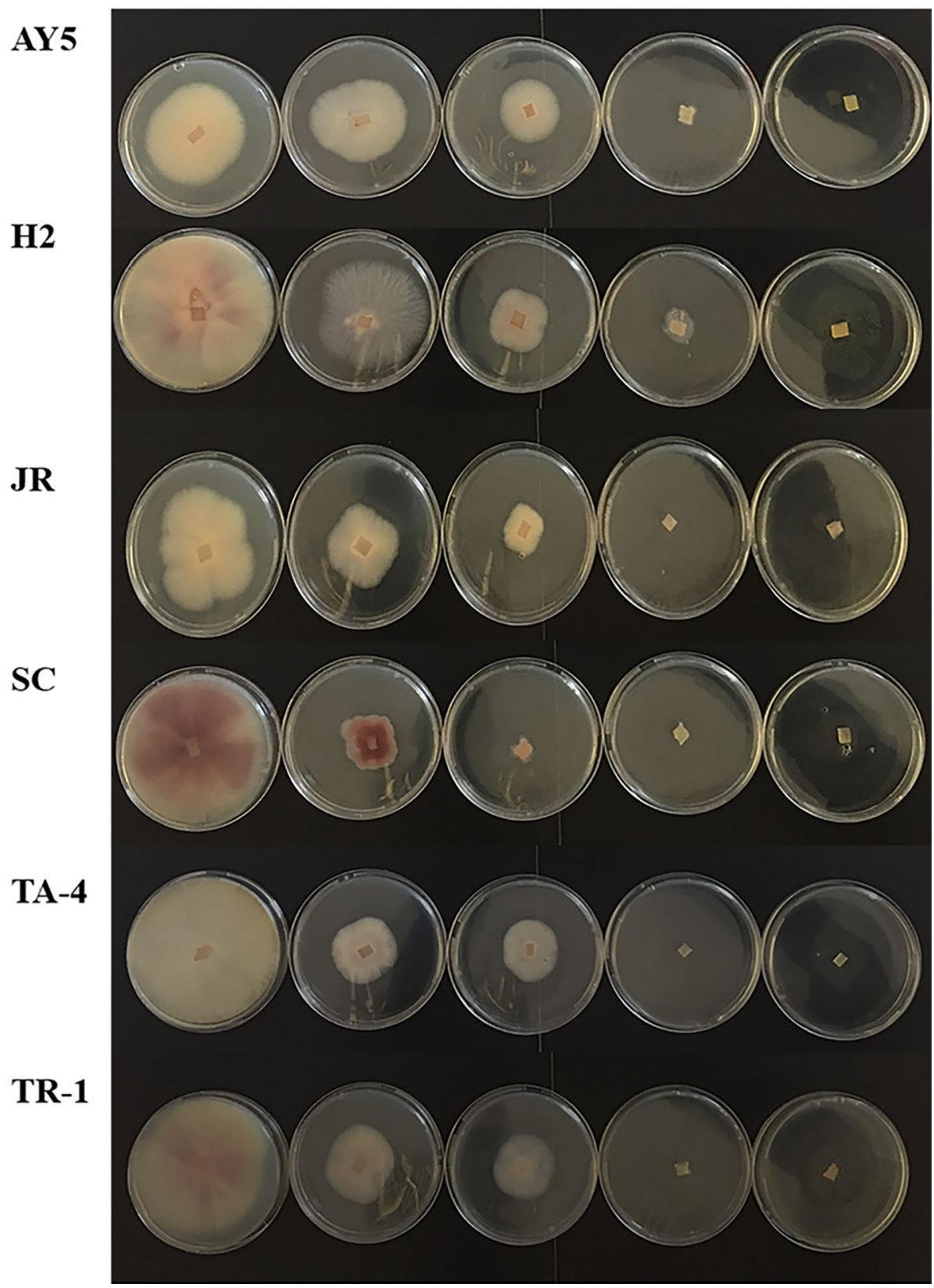

antifungal activity have been investigated against Fusarium species. Saharan et al. [41] synthesized and evaluated $\mathrm{Cu}$-chitosan nanoparticles against pathogenic fungi. $\mathrm{Cu}$ chitosan nanoparticles, at the concentration of $0.12 \%$, inhibited mycelium growth of Alternaria solani and Fusarium oxysporum by $70.5 \%$ and $73.5 \%$, respectively.

\subsection{Morphological characterization}

The morphological characterization of conidia of six different FORL strains was listed in Table 2. The average length of microconidia and macroconidia were varied from 3.59 to $5.52 \mu \mathrm{m}$ and from 9.85 to $15.98 \mu \mathrm{m}$, respectively. The maximum antifungal activities were determined at 37.5-50 ppm concentrations of AgNPs in both agar diffusion and broth dilution bioassays. Then dimensions of micro- and macro-conidia of FORL strains were measured after AgNPs treatments. These dimensions were decreased to 3.07-4.94 $\mu \mathrm{m}(p$-value $<0.05)$ for microconidia and 8.28-14.12 $\mu \mathrm{m}(p$-value $<0.05)$ for macroconidia. Similarly, septation numbers of both microconidia and macroconidia were decreased via AgNPs treatments compared to the control (Table 2). Our findings results were correlated with previous results. 
Table 1 Fungal growth inhibition ( $\mathrm{FGl}, \%)$ of different size $(3 \mathrm{~nm}$, $5 \mathrm{~nm}, 8 \mathrm{~nm}$, and $10 \mathrm{~nm}$ ) with various concentrations (12.5 ppm, $25 \mathrm{ppm}, 50 \mathrm{ppm}, 75 \mathrm{ppm}$, and $100 \mathrm{ppm}$ ) of silver nanoparticles against Fusarium oxysporum f. sp. radicis-lycopersici (FORL) strains in Potato Dextrose Broth medium

\begin{tabular}{|c|c|c|c|c|c|}
\hline \multirow{2}{*}{$\begin{array}{l}\text { Strains } \\
\text { (ppm) }\end{array}$} & \multirow[t]{2}{*}{ AgNP sizes } & \multicolumn{4}{|c|}{ AgNP concentrations } \\
\hline & & $3 \mathrm{~nm}$ & $5 \mathrm{~nm}$ & $8 \mathrm{~nm}$ & $10 \mathrm{~nm}$ \\
\hline \multirow[t]{5}{*}{ AY5 } & 12.5 & $28 \pm 2^{\mathrm{abc}}$ & $29 \pm 2^{\mathrm{abc}}$ & $32 \pm 2^{c}$ & $23 \pm 2^{c}$ \\
\hline & 25 & $29 \pm 4^{c}$ & $32 \pm 3^{c}$ & $27 \pm 4^{c}$ & $24 \pm 1^{c}$ \\
\hline & 50 & $71 \pm 2^{c}$ & $68 \pm 4^{c}$ & $70 \pm 1^{c}$ & $66 \pm 1^{\mathrm{ac}}$ \\
\hline & 75 & $69 \pm 4^{c}$ & $70 \pm 5^{c}$ & $71 \pm 2^{c}$ & $67 \pm 1^{c}$ \\
\hline & 100 & $68 \pm 3^{c}$ & $71 \pm 6^{c}$ & $73 \pm 3^{c}$ & $73 \pm 2^{c}$ \\
\hline \multirow[t]{5}{*}{$\mathrm{H} 2$} & 12.5 & $50 \pm 2^{\mathrm{bc}}$ & $49 \pm 2^{\mathrm{ac}}$ & $48 \pm 3^{b c}$ & $48 \pm 2^{c}$ \\
\hline & 25 & $94 \pm 4^{c}$ & $96 \pm 5^{c}$ & $96 \pm 4^{\mathrm{a}}$ & $98 \pm 5^{\mathrm{ab}}$ \\
\hline & 50 & $96 \pm 2^{c}$ & $97 \pm 1$ & $98 \pm 2$ & $98 \pm 4^{b}$ \\
\hline & 75 & $97 \pm 3$ & $97 \pm 2$ & $98 \pm 1^{\text {ac }}$ & $98 \pm 1$ \\
\hline & 100 & $96 \pm 4$ & $97 \pm 3$ & $98 \pm 5$ & $99 \pm 2$ \\
\hline \multirow[t]{5}{*}{$J R$} & 12.5 & $38 \pm 3^{c}$ & $40 \pm 4^{c}$ & $30 \pm 3^{\mathrm{ac}}$ & $36 \pm 4^{\mathrm{ac}}$ \\
\hline & 25 & $91 \pm 4^{c}$ & $90 \pm 2$ & $92 \pm 4$ & $89 \pm 2^{\mathrm{ac}}$ \\
\hline & 50 & $91 \pm 2$ & $90 \pm 1$ & $92 \pm 1$ & $90 \pm 1^{\mathrm{a}}$ \\
\hline & 75 & $92 \pm 1$ & $89 \pm 5$ & $93 \pm 2$ & $92 \pm 5$ \\
\hline & 100 & $91 \pm 2$ & $91 \pm 2$ & $93 \pm 4$ & $93 \pm 3$ \\
\hline \multirow[t]{5}{*}{ SC } & 12.5 & $40 \pm 4^{b c}$ & $15 \pm 3^{c}$ & $14 \pm 2^{c}$ & $3 \pm 1^{c}$ \\
\hline & 25 & $91 \pm 1^{c}$ & $93 \pm 4$ & $93 \pm 3$ & $93 \pm 2^{c}$ \\
\hline & 50 & $93 \pm 2^{c}$ & $95 \pm 1$ & $94 \pm 4$ & $94 \pm 4$ \\
\hline & 75 & $92 \pm 4$ & $96 \pm 2^{c}$ & $95 \pm 5^{c}$ & $96 \pm 3$ \\
\hline & 100 & $91 \pm 3$ & $95 \pm 4$ & $96 \pm 6$ & $96 \pm 2^{c}$ \\
\hline \multirow[t]{5}{*}{ TA-4 } & 12.5 & $54 \pm 4^{c}$ & $56 \pm 3^{\mathrm{abc}}$ & $47 \pm 4^{\mathrm{a}}$ & $45 \pm 2^{c}$ \\
\hline & 25 & $96 \pm 2^{c}$ & $91 \pm 2^{\mathrm{a}}$ & $87 \pm 2^{\mathrm{ab}}$ & $92 \pm 4^{c}$ \\
\hline & 50 & $97 \pm 1^{c}$ & $92 \pm 4$ & $92 \pm 1$ & $94 \pm 5$ \\
\hline & 75 & $97 \pm 5$ & $93 \pm 2$ & $94 \pm 4^{c}$ & $94 \pm 1$ \\
\hline & 100 & $97 \pm 2$ & $91 \pm 6$ & $95 \pm 2$ & $94 \pm 2$ \\
\hline \multirow[t]{5}{*}{ TR1 } & 12.5 & $31 \pm 2^{b c}$ & $37 \pm 3^{c}$ & $38 \pm 2^{\mathrm{ac}}$ & $19 \pm 3^{c}$ \\
\hline & 25 & $93 \pm 1^{c}$ & $94 \pm 2$ & $95 \pm 1$ & $94 \pm 2$ \\
\hline & 50 & $94 \pm 4$ & $94 \pm 2^{c}$ & $95 \pm 3$ & $94 \pm 1$ \\
\hline & 75 & $94 \pm 2$ & $95 \pm 2$ & $96 \pm 4^{c}$ & $94 \pm 2$ \\
\hline & 100 & $95 \pm 3$ & $96 \pm 3$ & $96 \pm 2$ & $95 \pm 2$ \\
\hline
\end{tabular}

Values are averages of 3 individual experiments. Data are given as mean values \pm standard deviations, which were calculated individually for each average. Means followed by a different letter(s) in the identical column differ significantly $(p=0.001)$ according to Tukey's test. $\mathrm{a}=p<0.05, \mathrm{~b}=p<0.01, \mathrm{c}=p<0.001$
Kheiri et al. [42] reported that chitosan and chitosanbased nanoparticles reduced the conidial germination of Fusarium graminearum. Chitosan-AgNP composite also reduced conidial germination and spore germination of Colletotrichum gloeosporioides [43]. Similarly, the treatments of chlorogenic acid, caffeic acid and coumarin could inhibit the germination of Fusarium oxysporum $\mathrm{f}$. sp. niveum (FON) conidia [44, 45].

\section{Conclusion}

Metal-based nanoparticles have been extensively studied for having antimicrobial activities. The AgNPs exhibited high antifungal and antibacterial activity with several previous reports $[39,46]$. Generally, a high concentration of AgNPs showed high antifungal activity against Fusarium strains. Different applications can be performed to use nanoparticles at lower concentrations. Nanoparticles size is also another important parameter affecting their antimicrobial efficiencies. For this, antifungal activities of nanoparticles in different concentrations and sizes were investigated.

Silver NPs exhibit high antifungal activity against plant pathogenic Fusarium oxysporum f. sp. radicislycopersici (FORL) strains at the concentrations around 37.5-50 ppm with low size. The results indicated that low AgNPs concentrations show efficient antifungal activity against Fusarium FORL species. As a result of the study, it can be said that silver nanoparticles can be used as plant protection in cultivating various agricultural products like tomato plants. However, further studies are needed to understand the toxicity of AgNPs before developing them for using in agricultural applications. Similarly, the different types and different sizes of metal-based nanoparticles might be tried for investigation of their antifungal activities against plant pathogenic fungi. Silver nanoparticles synthesized with natural phytochemicals, polypeptides or by several microorganisms might be also tested. 
Table 2 Average dimensions and septation numbers of both microconidia and macroconidia of Fusarium oxysporum f.sp. radicislycopersici (FORL) strains after treatment with AgNPs at $37.5 \mathrm{ppm}$ and $50 \mathrm{ppm}$ concentrations

\begin{tabular}{|c|c|c|c|c|c|}
\hline \multirow[t]{2}{*}{ Strains } & \multirow{2}{*}{$\begin{array}{l}\text { AgNPs } \\
\text { concentra- } \\
\text { tions }\end{array}$} & \multicolumn{2}{|l|}{ Microconidia } & \multicolumn{2}{|l|}{ Macroconidia } \\
\hline & & $\begin{array}{l}\text { Average dimensions } \\
\text { Length }(\mu \mathrm{m}) \times \text { width }(\mu \mathrm{m})\end{array}$ & $\begin{array}{l}\text { Septation } \\
\text { number }\end{array}$ & $\begin{array}{l}\text { Average dimensions } \\
\text { Length }(\mu \mathrm{m}) \times \text { width }(\mu \mathrm{m})\end{array}$ & $\begin{array}{l}\text { Septation } \\
\text { number }\end{array}$ \\
\hline \multirow[t]{3}{*}{ AY5 } & - & $3.64 \pm 0.35 \times 2.83 \pm 0.26$ & $1-2$ & $9.85 \pm 0.94 \times 3.10 \pm 0.24$ & $2-3$ \\
\hline & 37.5 ppm & $3.38 \pm 0.40 \times 2.36 \pm 0.03$ & $0-1$ & $9.73 \pm 0.87 \times 3.02 \pm 0.12$ & $1-2$ \\
\hline & $50 \mathrm{ppm}$ & $3.07 \pm 0.37 \times 2.00 \pm 0.23$ & 0 & $8.28 \pm 0.93 \times 2.98 \pm 0.34$ & $1-2$ \\
\hline \multirow[t]{3}{*}{$\mathrm{H} 2$} & - & $4.33 \pm 0.72 \times 2.36 \pm 0.12$ & $1-2$ & $15.98 \pm 0.97 \times 2.67 \pm 0.31$ & $3-4$ \\
\hline & 37.5 ppm & $4.26 \pm 0.83 \times 2.09 \pm 0.27$ & $1-2$ & $15.74 \pm 0.73 \times 2.65 \pm 0.11$ & $2-3$ \\
\hline & $50 \mathrm{ppm}$ & $3.89 \pm 0.10 \times 1.89 \pm 0.13$ & $0-1$ & $14.12 \pm 1.29 \times 2.53 \pm 0.07$ & $1-2$ \\
\hline \multirow[t]{3}{*}{$J R$} & - & $3.59 \pm 0.39 \times 2.19 \pm 0.39$ & $1-2$ & $10.32 \pm 0.52 \times 2.76 \pm 0.08$ & $2-3$ \\
\hline & 37.5 ppm & $3.36 \pm 0.41 \times 2.07 \pm 0.20$ & $0-1$ & $10.70 \pm 0.11 \times 2.56 \pm 0.36$ & $1-2$ \\
\hline & $50 \mathrm{ppm}$ & $3.37 \pm 0.39 \times 1.97 \pm 0.27$ & $0-1$ & $9.02 \pm 0.61 \times 2.37 \pm 0.46$ & $0-1$ \\
\hline \multirow[t]{3}{*}{ SC } & - & $5.52 \pm 0.19 \times 2.23 \pm 0.14$ & $1-2$ & $13.05 \pm 0.11 \times 2.81 \pm 0.16$ & $3-4$ \\
\hline & $37.5 \mathrm{ppm}$ & $5.19 \pm 0.40 \times 2.18 \pm 0.28$ & $0-1$ & $12.25 \pm 0.43 \times 2.73 \pm 0.33$ & $2-3$ \\
\hline & $50 \mathrm{ppm}$ & $4.94 \pm 0.15 \times 2.08 \pm 0.34$ & 0 & $11.45 \pm 0.54 \times 2.61 \pm 0.10$ & $2-3$ \\
\hline \multirow[t]{3}{*}{ TA-4 } & - & $3.69 \pm 0.43 \times 2.29 \pm 0.35$ & 1 & $12.32 \pm 0.26 \times 2.68 \pm 0.13$ & $3-4$ \\
\hline & 37.5 ppm & $3.59 \pm 0.29 \times 1.95 \pm 0.28$ & $0-1$ & $11.26 \pm 0.24 \times 2.54 \pm 0.19$ & $2-3$ \\
\hline & $50 \mathrm{ppm}$ & $3.47 \pm 0.42 \times 1.56 \pm 0.12$ & $0-1$ & $9.36 \pm 0.56 \times 2.41 \pm 0.21$ & $1-2$ \\
\hline \multirow[t]{3}{*}{ TR1 } & - & $3.82 \pm 0.70 \times 2.21 \pm 0.51$ & $1-2$ & $10.73 \pm 0.30 \times 2.93 \pm 0.86$ & $2-3$ \\
\hline & $37.5 \mathrm{ppm}$ & $3.64 \pm 0.53 \times 2.19 \pm 0.38$ & $1-2$ & $10.22 \pm 0.84 \times 2.81 \pm 0.44$ & $1-2$ \\
\hline & 50 ppm & $3.63 \pm 0.56 \times 2.13 \pm 0.43$ & $0-1$ & $10.20 \pm 0.42 \times 2.78 \pm 0.53$ & $1-2$ \\
\hline
\end{tabular}

Values are averages of 3 individual experiments. Data are given as mean values \pm standard deviations, which were calculated individually for each average
Acknowledgements We would like to thank Istanbul University for supporting this research, the grant number: FDK-2017-23670, Turkey.

Author contributions IA: Designed and performed research, analyzed data, wrote the manuscript, MU: Designed research, analyzed data, TS: Designed and performed research, analyzed data, wrote the manuscript.

Funding Open access funding provided by University of Borås.

\section{Declarations}

Conflict of interest On behalf of all authors, the corresponding author states that there is no conflict of interest.

Open Access This article is licensed under a Creative Commons Attribution 4.0 International License, which permits use, sharing, adaptation, distribution and reproduction in any medium or format, as long as you give appropriate credit to the original author(s) and the source, provide a link to the Creative Commons licence, and indicate if changes were made. The images or other third party material in this article are included in the article's Creative Commons licence, unless indicated otherwise in a credit line to the material. If material is not included in the article's Creative Commons licence and your intended use is not permitted by statutory regulation or exceeds the permitted use, you will need to obtain permission directly from the copyright holder. To view a copy of this licence, visit http://creativecommons. org/licenses/by/4.0/.

\section{References}

1. Çolak A, Biçici M (2013) PCR detection of Fusarium oxysporum $\mathrm{f}$. $\mathrm{sp}$. radicis-lycopersici and races of $F$. oxysporum f. sp. lycopersici of tomato in protected tomato-growing areas of the eastern Mediterranean region of Turkey. Turk J Agric For 37(4):457-467

2. Med AAE (2002) Toxin producing micromycetes on fruit, berries, and vegetables. Ann Agric Environ Med 9:183-197

3. Garrett SD (1970) Pathogenic root-infecting fungi. University Press, Cambridge

4. McGovern RJ (2015) Management of tomato diseases caused by Fusarium oxysporum. Crop Prot 73:78-92

5. Jabnoun-Khiareddine $H$, Abdallah RAB, Nefzi A, Ayed F, DaamiRemadi M (2019) Grafting tomato cultivars for soilborne disease suppression and plant growth and yield improvement. J Plant Pathol Microbiol 10:1-473

6. Özkara A, Akyıl D, Konuk M (2016) Pesticides, environmental pollution, and health. Environmental health risk-hazardous factors to living Species. IntechOpen

7. Kumari D, John S (2018) Safety and occupational health hazards of agricultural workers handling pesticides: a case study. Advances in health and environment safety. Springer, Singapore, pp 75-82

8. Lamsal K, Kim SW, Jung JH, Kim YS, Kim KS, Lee YS (2011) Application of silver nanoparticles for the control of colletotrichum species in vitro and pepper anthracnose disease in field. Mycobiology 39(3):194-199

9. Narware J, Yadav RN, Keswani C, Singh SP, Singh HB (2019) Silver nanoparticle-based biopesticides for phytopathogens: Scope 
and potential in agriculture. In: Koul O (ed) Biopesticides today and future perspectives. Academic Press, pp 303-314

10. Chen J, Wu L, Lu M, Lu S, Li Z, Ding W (2020) Comparative study on the fungicidal activity of metallic $\mathrm{MgO}$ nanoparticles and macroscale $\mathrm{MgO}$ against soilborne fungal phytopathogens. Front Microbiol 11:365

11. Kim JS, Kuk E, Yu KN, Kim JH, Park SJ, Lee HJ, Kim SH, Park YK, Park YH, Hwang C-Y, Kim Y-K, Lee Y-S, Jeong DH, Cho M-H (2007) Antimicrobial effects of silver nanoparticles. Nanomedicine (NBM) 3(1):95-101

12. Tien D-C, Tseng K-H, Liao C-Y, Tsung T-T (2008) Colloidal silver fabrication using the spark discharge system and its antimicrobial effect on Staphylococcus aureus. Med Eng Phys 30(8):948-952

13. Kasprowicz MJ, Kozioł M, Gorczyca A (2010) The effect of silver nanoparticles on phytopathogenic spores of Fusarium culmorum. Can J Microbiol 56(3):247-253

14. Loo YY, Rukayadi Y, Nor-Khaizura MAR, Kuan $\mathrm{CH}$, Chieng BW, Nishibuchi M, Radu S (2018) In vitro antimicrobial activity of green synthesized silver nanoparticles against selected gramnegative foodborne pathogens. Front Microbiol 9:1555

15. Raghupathi KR, Koodali RT, Manna AC (2011) Size-dependent bacterial growth inhibition and mechanism of antibacterial activity of zinc oxide nanoparticles. Langmuir 27(7):4020-4028

16. Kalia A, Abd-Elsalam KA, Kuca K (2020) Zinc-based nanomaterials for diagnosis and management of plant diseases: ecological safety and future prospects. J Fungi 6(4):222

17. Li Y, Chan YC (2015) Effect of silver (Ag) nanoparticle size on the microstructure and mechanical properties of $\mathrm{Sn} 58 \mathrm{Bi}-\mathrm{Ag}$ composite solders. J Alloys Compd 645:566-576

18. Pal S, Tak YK, Song JM (2007) Does the antibacterial activity of silver nanoparticles depend on the shape of the nanoparticle? A study of the gram-negative bacterium Escherichia coli. Appl Environ Microbiol 73(6):1712

19. Yamanaka M, Hara K, Kudo J (2005) Bactericidal actions of a silver ion solution on Escherichia coli, studied by energy-filtering transmission electron microscopy and proteomic analysis. Appl Environ Microbiol 71(11):7589

20. Pradeep T, Anshup (2009) Noble metal nanoparticles for water purification: a critical review. Thin Solid Films 517(24):6441-6478

21. Tankhiwale R, Bajpai SK (2009) Graft copolymerization onto cellulose-based filter paper and its further development as silver nanoparticles loaded antibacterial food-packaging material. Colloid Surface B 69(2):164-168

22. Abbasi E, Milani M, Fekri Aval S, Kouhi M, Akbarzadeh A, Nasrabadi HT, Nikasa P, Joo SW, Hanifehpour Y, Koshki KN, Samiei M (2016) Silver nanoparticles: synthesis methods, bio-applications and properties. Crit Rev Microbiol 42(2):173-180

23. Dakal TC, Kumar A, Majumdar RS, Yadav V (2016) Mechanistic basis of antimicrobial actions of silver nanoparticles. Front Microbiol 7:1831

24. Zhang X-F, Liu Z-G, Shen W, Gurunathan S (2016) Silver nanoparticles: synthesis, characterization, properties, applications, and therapeutic approaches. Int J Mol Sci 17(9):1534

25. da Silva BN, Nakassugi LP, Oliveira JFP, Kohiyama CY, Mossini SAG, Grespan R, Nerilo SB, Mallmann CA, Filho BAA, Machinski MM (2015) Antifungal activity and inhibition of fumonisin production by Rosmarinus officinalis L. essential oil in Fusarium verticillioides (Sacc.) Nirenberg. Food Chem 166:330-336

26. Pinto RJB, Almeida A, Fernandes SCM, Freire CSR, Silvestre AJD, Neto CP, Trindade T (2013) Antifungal activity of transparent nanocomposite thin films of pullulan and silver against Aspergillus niger. Colloid Surface B 103:143-148
27. Mulekar VG, Desai AG, Chavan AA (2017) Studies on morphological variability in Fusarium oxysporum f. sp. ricini causing wilt of castor. Trends in Biosci 10(4):1232-1236

28. Cioffi N, Torsi L, Ditaranto N, Tantillo G, Ghibelli L, Sabbatini L, Bleve-Zacheo T, D'Alessio M, Zambonin PG, Traversa E (2005) Copper nanoparticle/polymer composites with antifungal and bacteriostatic properties. Chem Mater 17(21):5255-5262

29. He L, Liu Y, Mustapha A, Lin M (2011) Antifungal activity of zinc oxide nanoparticles against Botrytis cinerea and Penicillium expansum. Microbiol Res 166(3):207-215

30. Kim SW, Jung JH, Lamsal K, Kim YS, Min JS, Lee YS (2012) Antifungal effects of silver nanoparticles (AgNPs) against various plant pathogenic fungi. Mycobiology 40(1):53-58

31. Lamsa K, Kim S-W, Jung JH, Kim YS, Kim KS, Lee YS (2011) Inhibition effects of silver nanoparticles against powdery mildews on cucumber and pumpkin. Mycobiology 39(1):26-32

32. Morones JR, Elechiguerra JL, Camacho A, Holt K, Kouri JB, Ramírez JT, Yacaman MJ (2005) The bactericidal effect of silver nanoparticles. Nanotechnology 16(10):2346

33. Kaur G, Kalia A, Sodhi HS (2020) Size controlled, time-efficient biosynthesis of silver nanoparticles from Pleurotus florida using ultra-violet, visible range, and microwave radiations. Inorg Nano-Met Chem 50(1):35-41

34. Li J, Rong K, Zhao H, Li F, Lu Z, Chen R (2013) Highly selective antibacterial activities of silver nanoparticles against Bacillus subtilis. J Nanosci Nanotech 13(10):6806-6813

35. Pujol I, Guarro J, Llop C, Soler L, Fernández-Ballart J (1996) Comparison study of broth macrodilution and microdilution antifungal susceptibility tests for the filamentous fungi. Antimicrob Agents Chemother 40(9):2106

36. Irkin R, Korukluoglu M (2009) Effectiveness of Cymbopogon citratus $L$. essential oil to inhibit the growth of some filamentous fungi and yeasts. J Med Food 12(1):193-197

37. Feng QL, Wu J, Chen GQ, Cui FZ, Kim TN, Kim JO (2000) A mechanistic study of the antibacterial effect of silver ions on Escherichia coli and Staphylococcus aureus. J Biomed Mater Res 52(4):662-668

38. Fernández JG, Fernández-Baldo MA, Berni E, Camí G, Durán N, Raba J, Sanz MI (2016) Production of silver nanoparticles using yeasts and evaluation of their antifungal activity against phytopathogenic fungi. Process Biochem 51(9):1306-1313

39. Gajbhiye M, Kesharwani J, Ingle A, Gade A, Rai M (2009) Fungus-mediated synthesis of silver nanoparticles and their activity against pathogenic fungi in combination with fluconazole. Nanomedicine (NBM) 5(4):382-386

40. Roy A, Bulut O, Some S, Mandal AK, Yilmaz MD (2019) Green synthesis of silver nanoparticles: biomolecule-nanoparticle organizations targeting antimicrobial activity. RSC Adv 9(5):2673-2702

41. Saharan V, Sharma G, Yadav M, Choudhary MK, Sharma SS, Pal A, Raliya R, Biswas P (2015) Synthesis and in vitro antifungal efficacy of $\mathrm{Cu}$-chitosan nanoparticles against pathogenic fungi of tomato. Int J Biol Macromol 75:346-353

42. Kheiri A, Jorf SAM, Malihipour A, Saremi H, Nikkhah M (2016) Application of chitosan and chitosan nanoparticles for the control of Fusarium head blight of wheat (Fusarium graminearum) in vitro and greenhouse. Int J Biol Macro 93:1261-1272

43. Chowdappa P, Gowda S, Chethana CS, Madhura S (2014) Antifungal activity of chitosan-silver nanoparticle composite against Colletotrichum gloeosporioides associated with mango anthracnose. Afr J Microbiol Res 8(17):1803-1812

44. Ling N, Zhang W, Wang D, Mao J, Huang Q, Guo S, Shen Q (2013) Root exudates from grafted-root watermelon showed a certain contribution in inhibiting Fusarium oxysporum f. sp. niveum. PLoS ONE 8(5):e63383-e63383 
45. Wu H-S, Raza W, Liu D-Y, Wu C-L, Mao Z-S, Xu Y-C, Shen Q-R (2008) Allelopathic impact of artificially applied coumarin on Fusarium oxysporum f. sp. niveum. World J Microb Biotech 24(8):1297-1304
46. Petica A, Gavriliu S, Lungu M, Buruntea N, Panzaru C (2008) Colloidal silver solutions with antimicrobial properties. Mater Sci Eng B 152(1):22-27

Publisher's Note Springer Nature remains neutral with regard to jurisdictional claims in published maps and institutional affiliations. 